\title{
Child marriage and associated outcomes in northern Ghana: a cross-sectional study
}

\author{
Richard de Groot ${ }^{1 *}$, Maxwell Yiryele Kuunyem², Tia Palermo ${ }^{1}$ on behalf of the Ghana LEAP 1000 evaluation team
}

\begin{abstract}
Background: Child marriage is a human rights violation disproportionately affecting girls in lower- and middleincome countries and has serious public health implications. In Ghana, one in five girls marry before their 18th birthday and one in 20 girls is married before her 15th birthday. This paper uses a unique dataset from Northern Ghana to examine the association between child marriage and adverse outcomes for women among a uniquely vulnerable population.

Methods: Baseline data from on ongoing impact evaluation of a government-run cash transfer programme was used. The sample consisted of 1349 ever-married women aged 20-29 years from 2497 households in the Northern and Upper East regions of Ghana. We estimated a series of ordinary least squares (OLS) and logistic regression models to examine associations of child marriage with health, fertility, contraception, child mortality, social support, stress and agency outcomes among women, controlling for individual characteristics and household-level factors.
\end{abstract}

Results: Child marriage in this sample was associated with increased odds of poorer health, as measured by difficulties in daily activities $(\mathrm{OR}=2.08 ; \mathrm{Cl} 1.28-3.38$ among women 20-24 years and $\mathrm{OR}=1.58 ; \mathrm{Cl} 1.19-2.12$ among women 2029 years), increased odds of child mortality among first-born children ( $\mathrm{OR}=2.03 ; \mathrm{Cl} 1.09-3.77$ among women 2024 years) and lower odds of believing that one's life is determined by their own actions ( $\mathrm{OR}=0.42 ; \mathrm{Cl} 0.25-0.72$ among women 20-24 years and $\mathrm{OR}=0.54 ; \mathrm{Cl} 0.39-0.75$ among women 20-29 years). Conversely, child marriage was associated with lower levels of reported stress (regression coefficient $=-1.18 ; \mathrm{Cl}-1.84--0.51$ among women 20-29 years).

Conclusions: Child marriage is common in Northern Ghana and is associated with poor health, increased child mortality, and low agency among women in this sample of extremely poor households. While not much is known about effective measures to combat child marriage in the context of Ghana, programmes that address key drivers of early marriage such as economic insecurity and school enrolment at the secondary level, should be examined with respect to their effectiveness at reducing early marriage.

Trial registration: Registered in the Registry for International Development Impact Evaluations (RIDIE) on 01 July 2015, with number RIDIE-STUDY-ID-55942496d53af.

Keywords: Child marriage, women's health, Ghana, Sub-Saharan Africa

\section{Background}

Child marriage is a human rights violation and has adverse effects on the children (overwhelmingly girls) who enter into these marriages, and on their future children, creating an intergenerational cycle of disadvantage. Sometimes referred to as early marriage, child marriage is defined as a marriage occurring when one of the

\footnotetext{
*Correspondence: rdegroot@unicef.org

'UNICEF Office of Research—Innocenti, Piazza SS. Annunziata 12, 50122

Florence, Italy

Full list of author information is available at the end of the article
}

spouses is younger than 18 years at the time of marriage or official union [1].

Rates of child marriage (typically measured as the share of women 20 to 24 years old who first married or entered into union before age 18) are highest in lowincome countries [2]. Data from 2012 from 41 lowincome countries indicated that the global rate of child marriage was $30 \%$, with a high of $75 \%$ in Niger [2]. Even within low-income countries, disparities exist and child marriage is more common among girls in rural areas, 
those with low educational attainment and those in the poorest socioeconomic strata [3, 4]. Trends in subSaharan Africa over the past 20 years are not always encouraging; while the prevalence of child marriage has decreased in most countries, these decreases have stalled in many countries, including Niger, Malawi, Kenya and Senegal [5].

Factors that contribute to child marriage include economic drivers, such as incentives to marry out girls to reduce the financial burden on the household or receive the bride price [6]. Other factors include social norms and the need to reinforce social ties and perceived protection. That is, parents often believe that they may be able to improve their social status through their daughter's marriage, linking two families together. Alternatively, parents may hold the belief that by marrying their daughter at an early age, she will be protected from sexual abuse, unwanted pregnancies and the risk of sexually transmitted infections [6, 7].

Negative health consequences of child marriage include poorer maternal and reproductive health, increased risk of HIV and other sexually transmitted infections, intimate partner violence and maternal mortality [7-10]. Moreover, early childbearing increases risks to women's health, as maternal disorders ${ }^{1}$ including complications during pregnancy and child birth are the leading cause of death among women aged 20-24 years globally and the second leading cause among adolescent girls aged 15 to 19 years [11]. In addition, girls who marry early are at a higher risk of intimate partner violence, poorer mental health and limited decision making power due to power imbalances within their marriage $[6,9,10]$. Child marriage is also associated with adverse economic outcomes, including lower educational attainment, lower socioeconomic status, and higher rates of poverty [12]. Further, the adverse consequences of early marriage are intergenerational. Children born to women affected by child marriage have higher mortality rates, are more likely to be born prematurely or with low birthweight and have poorer health and nutritional status $[13,14]$.

\section{Ghanaian context}

In Ghana, a lower-middle-income country, child marriage is prohibited under the constitution and by law. According to the Ghanaian constitution of 1992, any person under the age of 18 is a child and can therefore not marry or be married off. This is underscored by the 1998 Children's Act, which sets the legal age of marriage at 18 for both boys and girls [15].

Despite this legal framework, the prevalence of child marriage in Ghana remains high, and one in five girls marries before her 18th birthday (20.7\%) and one in 20 girls (4.9\%) marries before her 15th birthday [16]. Although child marriage can occur among males as well, the prevalence is much lower: only $2.3 \%$ of men aged 20 to 24 years are married by age 18 in Ghana [16]. The highest prevalence of child marriage in Ghana occurs in the three Northern regions, where more than one in three girls marry before age 18 . In addition, the child marriage rate is higher in rural areas, among the poorest population and among uneducated women. The aggregate rate of marriage before age 18 has been decreasing from $35 \%$ in the 1990 s to $28 \%$ in 2003 and $25 \%$ in 2008 , but remained stable between 2011 and 2014. However, data from the latest two nationally representative surveys shows that the rate of child marriage increased in the three Northern regions (from $26.4 \%$ in 2011 to $33.6 \%$ in 2014) and decreased in the other regions (from 20.9 to $18.5 \%$ and from 19.2 to $18.5 \%$ in the Central and Southern regions respectively), increasing disparities between the North and the rest of the country. ${ }^{2}$

Despite a large global evidence base on the consequences of child marriage, in-depth studies studying dynamics and consequences of child marriage in Ghana specifically are scarce. A better understanding of the dynamics around child marriage is important to motivate more action around reducing child marriage rates, particularly given that decreases have stalled in recent years, and to inform programming assisting child brides. In addition, existing datasets commonly used to study adverse impacts of child marriage, including Demographic and Health Surveys (DHS) and Multiple Indicator Cluster Surveys (MICS), aim to be comparable across countries and thus may not include all of the indicators of interest. Using a unique dataset from extremely poor households in two regions in Northern Ghana, the region identified as having the highest child marriage rates, this paper explores the relationship between child marriage and adverse outcomes among women and their children and also contributes to the literature by implementing innovative measures related to women's empowerment, a concept of widespread interest in development but one that is notoriously hard to measure in all its dimensions.

More specifically, we examined the following research question: To what extent is child marriage associated with adverse outcomes, including general health, reproductive health, agency, social support, and stress? We first examined associations between child marriage and outcomes examined in the existing evidence base (including general health, reproductive health and child mortality) using our data to investigate whether these relationships also hold in this setting. Next, we improve upon the existing evidence base by testing the association of child marriage with other outcomes of interest. One such outcome is women's empowerment, which Kabeer (1999) argued entails a process of change and defined the term as "the expansion in people's ability to make strategic life choices in a context where this ability 
was previously denied to them" (p. 437). In this process, resources, agency and achievements are inter-related dimensions relating to the ability to exercise choice. In the current study, we focus on the agency dimension, using an innovative measure of agency based on the locus of control (described in more detail in the methods section). This is an improvement on commonly used measures of women's empowerment, namely decisionmaking indices assessing women's self-reported participation in typical household decisions. Such indices have limitations in their ability to capture empowerment and dynamics around decision-making [17].

Additionally, we assessed another innovative aspect of women's empowerment: financial control and savings, which may reflect a woman's higher bargaining power within the household [18], an outcome not commonly examined in existing studies on child marriage.

Finally, we examined measures related to social support and stress. Women who marry early may have lower levels of social support for a variety of reasons, for example by being forced to move in with the husband's family, away from their peers in school, limiting access to social networks and friends [7, 19]. In addition, stress is both an important indicator of well-being in its own right $[20,21]$ but also a hypothesized pathway through which poverty and adverse life events may contribute to adverse outcomes [22]. In the context studied here, early marriage may induce stress as females newly navigate partnerships, new duties, childbearing and possibly violence. Further, given that poverty is a driver of child marriage $[2,6,7,19,23]$, and poverty is strongly associated with stress and poor mental health, [24-26], early marriage, poverty and stress may be mutually reinforcing.

Informed by the evidence to date, we hypothesized that child marriage is associated with lower levels of general health and worse reproductive health outcomes, including higher likelihood of adolescence childbearing and increased child mortality. ${ }^{3}$ We further hypothesized that child marriage is associated with lower levels of agency, lower levels of social support and higher levels of self-perceived stress.

\section{Methods}

\section{Sample}

Data for this study come from the baseline survey of a longitudinal impact evaluation of the Livelihood for Empowerment Against Poverty (LEAP) 1000 programme. This is a government-run unconditional cash transfer programme targeted to pregnant women and women with children under the age of 15 months in extremely poor households, aimed at reducing poverty, increasing consumption and improving child nutrition. The programme was first rolled out in ten districts in
Northern Ghana (three districts in Upper East region and seven in Northern region), and communities within these districts were targeted based on official poverty rankings established at district level. UNICEF Office of Research - Innocenti in collaboration with the Institute of Statistical, Social and Economic Research (ISSER) at the University of Ghana and the University of North Carolina at Chapel Hill (USA) carried out an impact evaluation of the LEAP 1000 roll-out in five of the 10 implementing districts between 2015 and 2017. Study eligibility criteria reflects the programme targeting, namely pregnant women and women (ages 15 to 49) with children under the age of 15 months in poor, rural households living in the Northern or Upper East region of Ghana. Households surveys were administered to the LEAP 1000 eligible woman (referred to as the "main respondent") in each selected household.

Data used in the current study come from the baseline survey of this impact evaluation, which was administered from July through September 2015 to 2497 women who met the eligibility criteria. ${ }^{4}$ Respondents and their households were quite homogenous in terms of socioeconomic status, with approximately $90 \%$ of the sample living below the national poverty line of US\$ 1.83 per adult per day [27]. ${ }^{5}$ The typical age group for studying child marriage is among ever-married women 20 to 24 years old $[2,28]$. However, since this age range does not provide a sufficient sample for analysis in our data, we also use the broader age range of ever-married 20 to 29 years old for analyses in the current sample. These restrictions result in an analysis sample of 594 women 20 to 24 years old and 1349 total women 20 to 29 years old (Table 1).

\section{Measures}

The main independent variable in this analysis, child marriage, is based on the self-reported age at which the respondent got married or started living together with a partner for the first time. Women reporting marriage or cohabitation before the age of 18 were defined as experiencing child marriage.

Health outcomes examined included recent illness (defined as any illness in the last 14 days) and whether the woman reports having a valid $\mathrm{Na}$ tional Health Insurance Scheme (NHIS) card (yes/ no). ${ }^{6}$ Subjective health was assessed through a selfreported question with five response options (poor, fair, good, very good and excellent), which has been found to be a good predictor of future mortality and morbidity [29]. We constructed a dummy indicator equal to one if a respondent reported poor or fair health and equal to zero otherwise. A second subjective health outcome was created from a question asking whether the respondent believed her health was 
Table 1 Sample characteristics, Women aged 20-29 years, Ghana LEAP 1000 Baseline

\begin{tabular}{|c|c|c|c|c|}
\hline & \multicolumn{2}{|c|}{ Ever-married women 20 to 24 years old } & \multicolumn{2}{|c|}{ Ever-married women 20 to 29 years old } \\
\hline & $\mathrm{N}$ & $\%$ & $\mathrm{~N}$ & $\%$ \\
\hline \multicolumn{5}{|l|}{ Age } \\
\hline 20 to 24 years & 594 & 100.0 & 594 & 44.0 \\
\hline 25 to 29 years & & & 755 & 56.0 \\
\hline \multicolumn{5}{|l|}{ Educational achievement } \\
\hline No schooling & 407 & 68.5 & 1000 & 74.1 \\
\hline Some primary & 50 & 8.4 & 117 & 8.7 \\
\hline Primary completed or higher & 137 & 23.1 & 232 & 17.2 \\
\hline \multicolumn{5}{|l|}{ Region of residence } \\
\hline Northern & 414 & 69.7 & 976 & 72.4 \\
\hline Upper East & 180 & 30.3 & 373 & 27.7 \\
\hline \multicolumn{5}{|l|}{ Marital status } \\
\hline Married/Union - Monogamous & 441 & 74.2 & 913 & 67.7 \\
\hline Married/Union - Polygamous & 148 & 24.9 & 418 & 31.0 \\
\hline Separated/Divorced/Widowed & 5 & 0.8 & 18 & 1.3 \\
\hline \multicolumn{5}{|l|}{ Child marriage status } \\
\hline Married after 18th birthday & 416 & 70.0 & 1018 & 75.5 \\
\hline Married between 15 - 18th birthday & 154 & 25.9 & 284 & 21.1 \\
\hline Married before 15th birthday & 24 & 4.0 & 47 & 3.5 \\
\hline
\end{tabular}

better than one year ago (yes/no). The final health outcome assessed difficulties with activities of daily living (ADL; items include carrying a $10 \mathrm{~kg}$ load for $500 \mathrm{~m}$; bend, squat or kneel; and walking a distance of $2 \mathrm{~km})$. Respondents were asked if they could do each of these activities easily, with difficulty or could not do the activity at all. If a respondent indicated 'with difficulty' or 'not at all' for any of these activities, she was classified as having an ADL difficulty. All health outcomes are coded such that a positive value indicates an adverse health outcome.

The second set of outcomes examined relate to fertility, contraception and child mortality. Fertility-related outcomes examined included age at first birth and adolescent childbearing (giving birth to a child before age 20). We also examined current use of modern contraceptives and unmet need for contraceptives (defined as when a woman reported not wanting any more children but was not using any contraceptive). Modern contraceptives were defined as female/male sterilization, intrauterine device (IUD), injectable, implant, pill, male/female condom, diaphragm, or foam/jelly. Traditional methods were lactational amenorrhoea method (LAM), periodic abstinence or withdrawal and were also considered for the 'any contraceptives' indicator. Finally, child mortality was examined for the firstborn child. ${ }^{7}$

Next, we assessed the savings behaviour of the women, as a proxy for their control over household resources. We asked whether women were currently saving any money in cash and created a variable equal to one if a respondent reported to be currently saving money and equal to zero otherwise.

Stress was measured by the Perceived Stress Scale (PSS), consisting of ten questions, six negatively phrased and four positively phrased assessing the degree to which individuals experience their lives as unpredictable, uncontrollable and overloading [30]. The PSS has been validated in countries across the world and is increasingly being used in Sub-Saharan Africa [31-33], though has not been validated in the African setting to date. Responses included Likerttype options ranging from 0 (never) to 4 (very often/always). The scale was constructed by first reverse coding positive items and then adding the total score from each question resulting in a scale ranging from 0 to 50 , where a higher score indicates higher stress. Cronbach's alpha, which tests internal consistency of a set of scale items, for this scale was 0.67 .

To measure social support, the survey employed the eight-item modified Medical Outcomes Study Social Support Survey (mMOS-SS) [34]. Items in this scale include questions such as: whether the individual has someone who would help them if they were confined to bed, take them to the doctor if they need it, prepare their meals if they are unable to do it themselves, help with daily chores if they are sick, have a good time with, turn to for suggestions about dealing with a personal problem, someone to 
understand their problems, and having someone to love and make them feel wanted. Response options on a Likerttype scale ranged from 1 (none of the time) to 5 (all of the time). The score was obtained by averaging the responses to the items and then standardizing them, resulting in a score with a possible range from 0 to 100 , where higher scores indicate higher social support levels. Cronbach's alpha for the eight statements is 0.90 .

Finally, women's agency was operationalized via a locus of control index measured by a Likert scale from 1 (none of the time) to 5 (all of the time). The scale has been loosely based on Rotter's internal versus external locus of control scale [35], yet we have contextualized it to better match our research population and study objectives. More specifically, we employed the following six statements: Your life is determined by your own actions; You have the power to make important decisions that change the course of your own life; You have the power to make important decisions that change the wellbeing of your children; You have the power to make important decisions that change the wellbeing of your household; You are capable of protecting your own interests within your household; You are capable of protecting your own interests outside of your household (e.g. in the community, in groups in which you participate). Internal consistency among the statements is high, with Cronbach's alpha of 0.79 . The six statements are each dichotomized by coding the indicator as one for response options most/all of the time and zero otherwise. Individual items in the scale have been found to be positively affected by cash and in-kind transfers in Ecuador [36], and an index using similar questions predicted the level of impatience and demand for commitment and saving in rural Ethiopia [37].

\section{Data analysis}

We first summarized background characteristics and outcome indicators. Next, we examined subsequent risks associated with child marriage, by estimating a series of regression models (logistic for dichotomous outcome variables and ordinary least squares (OLS) for continuous outcomes) for each of the outcomes described above. Controls used in this analysis included individual characteristics (age and highest educational attainment), household-level factors (household size; number of members in each of the following age groups: 0 to 5 years, 6 to 12 years, 13 to 17 years, 18 to 24 years, 25 to 34 years, 35 to 44 years, 45 to 54 years, and 55 to 64 years; sex of the head of household; whether the head of household had ever attended school; log of monthly household adult equivalent consumption in Ghana cedi) and a dichotomous variable for each of the districts Karaga, Yendi, Bongo and Garu-Tempane.

We estimated all regressions on two subgroups of women who have ever been married or cohabited. First, we take the typical age group for research on child marriage: 20 to 24 years. Due to relatively small sample size for some of our outcomes in this age group, we also estimate our regressions on a larger subsample of women: 20 to 29 years. Sample sizes for regressions run on different outcomes varies, as information on contraceptive use, empowerment, social support, stress and time preferences were collected among only one women per household (the main survey respondent), while outcomes such as general health and reproductive health are available for all women of reproductive age in the households.

All analyses were run with Stata 14.2 (College Station, TX) and in multivariate analyses, standard errors were adjusted in all analyses to account for clustering at the community-level.

\section{Results}

\section{Sample characteristics}

Table 1 provides descriptive statistics stratified by age group. Educational attainment of the women in the sample is low, with close to $70 \%$ attaining no education at all in the 20 to 24 year age group ( $75 \%$ in the 20 to 29 year age group). Most of the women live in the Northern region of Ghana, which is also a reflection of the targeting of the cash transfer programme, and a majority of women are in a monogamous marriage or union. However, polygyny is common, with $25 \%$ of woman in the 20 to 24 year age group in a polygamous marriage or union (31\% of women aged 20 to 29 years). The child marriage rate in the 20 to 24 year age group is $30 \%$. Approximately $4 \%$ of 20 to 24 year olds married before age 15 . In the 20 to 29 year age group, approximately one in four women married before age 18 and $3.5 \%$ before age $15 .^{8}$

Table 2 depicts the means and standard deviations of the outcomes examined in this study. Approximately one third of the sample ( $24 \%$ of those 20 to 24 years) reports having an illness in the last 2 weeks, and $21 \%$ of the sample (18\%) self-report being in fair or poor health. Further, 44\% (46\%) report not having a valid NHIS card. With respect to fertility and contraception, the average age of first birth in our sample was 19 years, and $45 \%$ (47\%) report having their first birth during adolescence. Rates of modern contraceptive use were $14 \%$ (12\%). This low rate (compared to 21 to $24 \%$ of women aged 20 to 29 years nationally using a modern method [16]) likely reflects both poverty-related contraceptive-access barriers as well as study eligibility criteria (pregnancy and post-pregnancy), when women are less likely to be using contraception. Very few women report currently saving money in cash (6\% of the full sample and $4 \%$ of the 20 to 24 year olds), reflecting general conditions of poverty in this sample. Further, in the agency (empowerment) 
Table 2 Means and standard deviations of outcome variables, Women aged 20-29 years, Ghana LEAP 1000 Baseline

\begin{tabular}{|c|c|c|c|c|c|c|}
\hline & \multicolumn{3}{|c|}{ Ever-married women 20 to 24 years old } & \multicolumn{3}{|c|}{ Ever-married women 20 to 29 years old } \\
\hline & $\mathrm{N}$ & Mean & SD & $\mathrm{N}$ & Mean & SD \\
\hline \multicolumn{7}{|l|}{ Health outcomes } \\
\hline Illness in last 2 weeks & 594 & 0.24 & 0.43 & 1349 & 0.30 & 0.46 \\
\hline No valid NHIS card & 594 & 0.46 & 0.50 & 1348 & 0.44 & 0.50 \\
\hline Fair/poor self-rated health & 516 & 0.18 & 0.38 & 1174 & 0.21 & 0.41 \\
\hline Believes health is not better than a year ago & 516 & 0.52 & 0.50 & 1174 & 0.54 & 0.50 \\
\hline Has difficulty with $\mathrm{ADL}$ & 516 & 0.48 & 0.50 & 1174 & 0.50 & 0.50 \\
\hline \multicolumn{7}{|l|}{ Fertility, contraception, and child mortality } \\
\hline Age of first birth & 493 & 18.93 & 2.25 & 1150 & 19.32 & 2.71 \\
\hline Adolescence childbearing & 594 & 0.47 & 0.50 & 1349 & 0.45 & 0.50 \\
\hline First born child died & 495 & 0.08 & 0.27 & 1152 & 0.10 & 0.30 \\
\hline Use any contraceptive & 447 & 0.12 & 0.32 & 1025 & 0.15 & 0.36 \\
\hline Use modern contraceptive & 447 & 0.12 & 0.32 & 1025 & 0.14 & 0.34 \\
\hline Unmet need for contraception & 447 & 0.03 & 0.17 & 1025 & 0.03 & 0.17 \\
\hline \multicolumn{7}{|l|}{ Empowerment, agency, support \& stress } \\
\hline Currently saving money & 516 & 0.04 & 0.20 & 1174 & 0.06 & 0.24 \\
\hline Believes life determined by own actions & 516 & 0.21 & 0.41 & 1174 & 0.22 & 0.41 \\
\hline Believes have power to make decisions - life course & 516 & 0.21 & 0.40 & 1174 & 0.22 & 0.41 \\
\hline Believes have power to make decisions - children's wellbeing & 516 & 0.14 & 0.35 & 1174 & 0.16 & 0.37 \\
\hline Believes have power to make decisions - household wellbeing & 516 & 0.09 & 0.29 & 1174 & 0.11 & 0.32 \\
\hline Believes capable protecting own interests within family & 516 & 0.10 & 0.30 & 1174 & 0.12 & 0.32 \\
\hline Believes capable protecting own interests outside family & 516 & 0.11 & 0.31 & 1174 & 0.15 & 0.36 \\
\hline MOS-Social Support score & 516 & 53.34 & 23.25 & 1174 & 51.99 & 22.74 \\
\hline Cohen perceived stress scale & 516 & 21.00 & 4.70 & 1174 & 21.64 & 4.94 \\
\hline
\end{tabular}

scale, the percentage reporting they believe they have the power to make decisions related to the various items range from $11 \%$ (household well-being (9\%)) to $22 \%$ (life course (21\%)). Averages on the MOS-SS and Cohen perceived stress scales were 51.99 (53.34) and 21.64 (21), respectively.

Association between child marriage and health outcomes Figure 1 presents outcomes related to general health. ${ }^{9}$ Child marriage was associated with increased likelihood of having $\mathrm{ADL}$ difficulties $(\mathrm{OR}=2.08$; CI 1.28-3.38 among women 20 to 24 years and $\mathrm{OR}=1.58$; CI 1.192.12 among women 20 to 29 years). There was no relationship between child marriage and illness, having a valid NHIS card, self-rated health, or self-reported improved health compared to one year prior.

\section{Association between child marriage and fertility outcomes, contraception and child mortality}

Results related to fertility are reported in Fig. 2A (dichotomous outcomes) and Fig. 2B (continuous outcomes). Child marriage was associated with earlier childbearing; the mean age at the birth of their first child is approximately two years younger for women who married as children compared to women who married as adults (Regression Coefficient $(\mathrm{RC})=-1.98 ; \mathrm{CI}-2.36--1.59$ among the 20 to 24 year old sample; $\mathrm{RC}=-2.14 ; \mathrm{CI}-2.44--1.83$ among the 20 to 29 year old sample). This is also reflected in the likelihood of adolescence childbearing, which is much higher among women marrying before age $18(\mathrm{OR}=4.97$; CI 3.15-7.86 among women 20 to 24 years and OR = 5.71; CI 4.06-8.05 among women 20 to 29 years). Further, firstborn children of women who married before age 18 had increased odds of child mortality, compared to first-borns of women who married after 18 years $(\mathrm{OR}=2.03$; CI 1.09 3.77 among women 20 to 24; not statistically significant among women 20 to 29 years). Child marriage was not associated with differences in current contraceptive use, either traditional or modern, or unmet need for contraception. ${ }^{10}$

\section{Association between child marriage and empowerment, social support and stress}

In Fig. 3A (dichotomous outcomes) and Fig. 3B (continuous outcomes) we present findings related to savings, support, self-perceived stress and agency. Child marriage was associated with lower levels of reported stress in the 20 to 


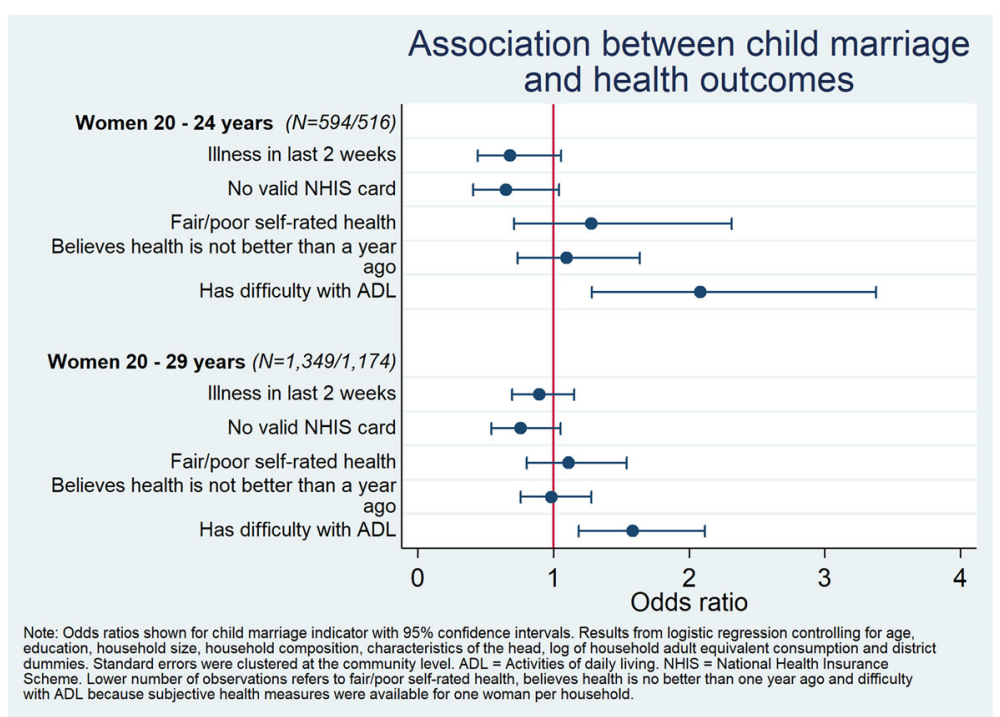

Fig. 1 Odds ratios (95\% confidence interval) of the association between child marriage and health outcomes, Women 20-29 years, Ghana LEAP 1000 Baseline

29 year age group (Coefficient $=-1.18$; CI $-1.84--0.51$ ), but not among those ages 20 to 24 years. In contrast, women married as children had lower odds of believing that their life was determined by their own actions (OR = 0.42; CI $0.25-0.72$ among women 20 to 24 years and OR $=0.54$; CI 0.39-0.75 among women 20 to 29 years). There was no significant relation between child marriage and saving, social support, or the remaining agency statements in this sample.

\section{Discussion}

In this paper, we examined child marriage rates among an extremely poor population in northern Ghana, a region with among the highest rates of child marriage in the country. We found that child marriage was associated with increased likelihood of difficulties with ADLs, higher likelihood of adolescence pregnancy, a higher likelihood of child mortality among first-born children (only among women 20 to 24 year old) and lower odds of believing that life is determined by one's own actions. Our unique data allow us to examine outcomes not generally measured in other studies on child marriage, including those related to savings, agency, social support and stress. Nevertheless, we found few associations between child marriage and these outcomes. There was no relationship between child marriage and illness, having a valid NHIS card, self-rated health, self-reported improved health compared to one year prior, current contraceptive use, unmet need for contraception, saving, social support, or the remaining agency statements.

Some of our findings are consistent with evidence from other countries and regions. For example, previous studies have shown significant risks for children born to teenage brides, such as premature birth, low-birth weight and a higher likelihood of dying before their second birthday $[6,10]$. The finding that child marriage was associated with adolescent child bearing reflects norms whereby girls and women are expected to start bearing children soon after marriage. We find that child marriage was associated with child mortality among women 20 to 24 years old, and previous studies support the links between child marriage and poor child health [6]. Hence, efforts to improve early childhood nutrition should be linked to programming aimed at reducing child marriage, as well as that addressing nutrition needs of pregnant adolescents or adolescent girls more generally in areas with high rates of early marriage. In this way, initiatives can have beneficial impacts for adolescent girls as well as their future children, helping to break the inter-generational cycle of poverty and poor health. To the best of our knowledge, previous studies have not examined the association between child marriage and ADL difficulties, but a common finding in the literature is that child marriage is associated with poorer general health outcomes [19].

In addition, the finding that child brides were less likely to believe that their life was determined by their own actions was in line with our expectations, given evidence that young wives have typically little bargaining power within the household [19]. Still, our findings on stress may somewhat contradict existing research on mental health, which find that child marriage is associated with poorer mental health, such as a suicidality, lack of self-esteem and depression [7, 38]. However, we are not aware of any studies on child marriage and subsequent stress. 


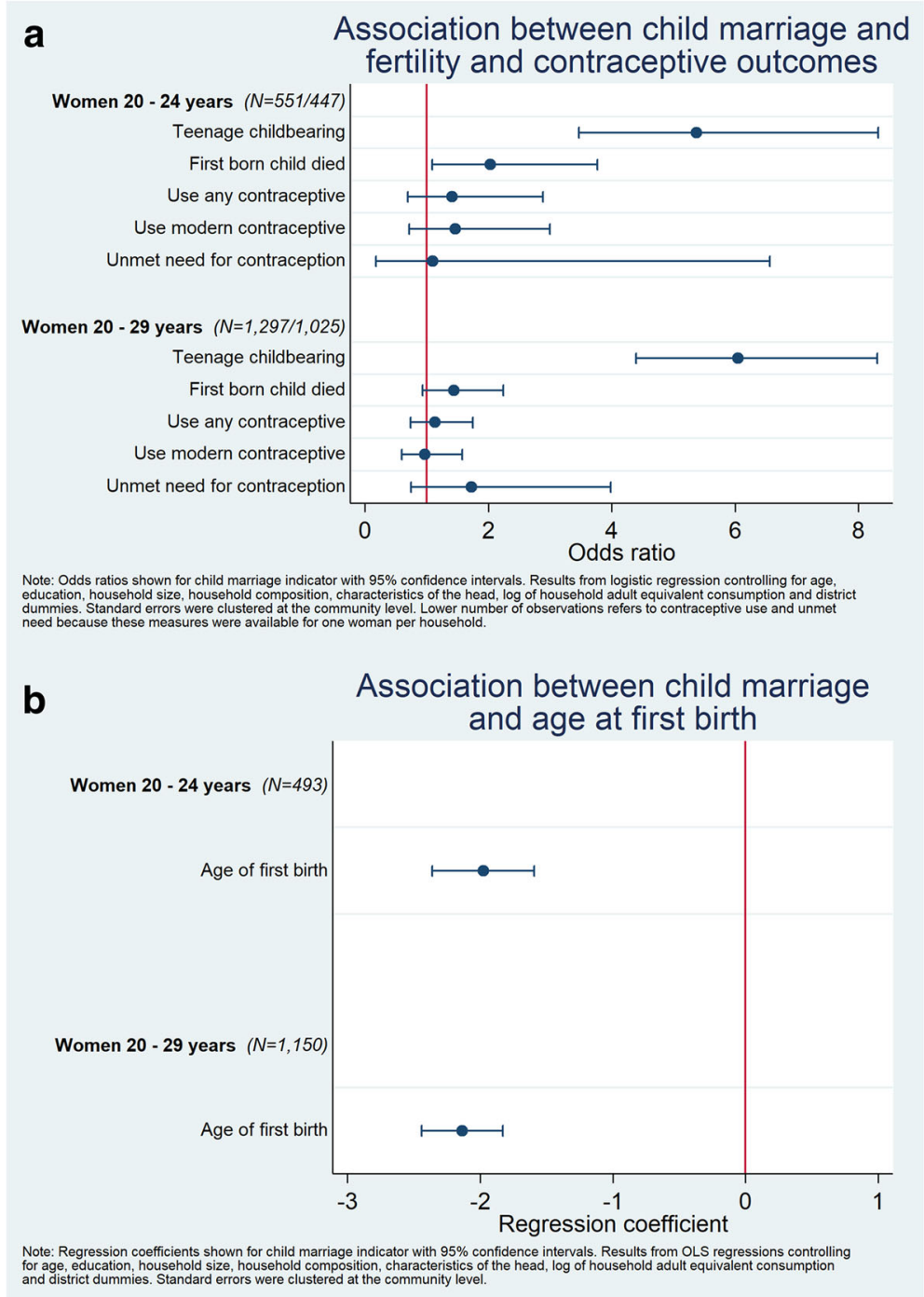

Fig. 2 a Odds ratios (95\% confidence interval) of the association between child marriage and fertility, contraceptive use, and child mortality among women whom ever gave birth, Women 20-29 years, Ghana LEAP 1000 Baseline. b Regression coefficients (95\% confidence interval) of the association between child marriage and age at first birth, among women whom ever gave birth, Women 20-29 years, Ghana LEAP 1000 Baseline

As with any research, there are limitations to this paper. Given the cross-sectional nature of the data (we examine both the self-report of child marriage and outcomes at the same time), we cannot control for the potential endogeneity of the marriage decision (i.e., are there unobserved factors driving both the child marriage decision and the observed outcomes). For example, poorer health outcomes and child marriage may be linked to other common factors such as poverty, social norms and expectations in the "sending" households (that is, households that are making the decision to marry off girls at an early age). Our data only represent "receiving" households, which is not an ideal study design to study impacts of child marriage, but is similar to existing studies in the public health literature examining associations between early marriage and adverse outcomes using cross-sectional data. However, given the homogeneity of the study sample (similar levels of poverty and area of residence) our estimates may better isolate the impacts of early marriage as compared to other studies and more heterogeneous samples, where poverty and related factors may drive both early marriage and adverse outcomes, biasing estimates of these relationships. In addition, the findings reported here are specific to a geographical location and demographic group, namely pregnant women or women with an infant in two Northern regions in Ghana. Thus our findings are not necessarily generalizable to the country as a whole, although many of the results are in line with findings from other studies.

While this paper has demonstrated adverse outcomes associated with child marriage among females, 


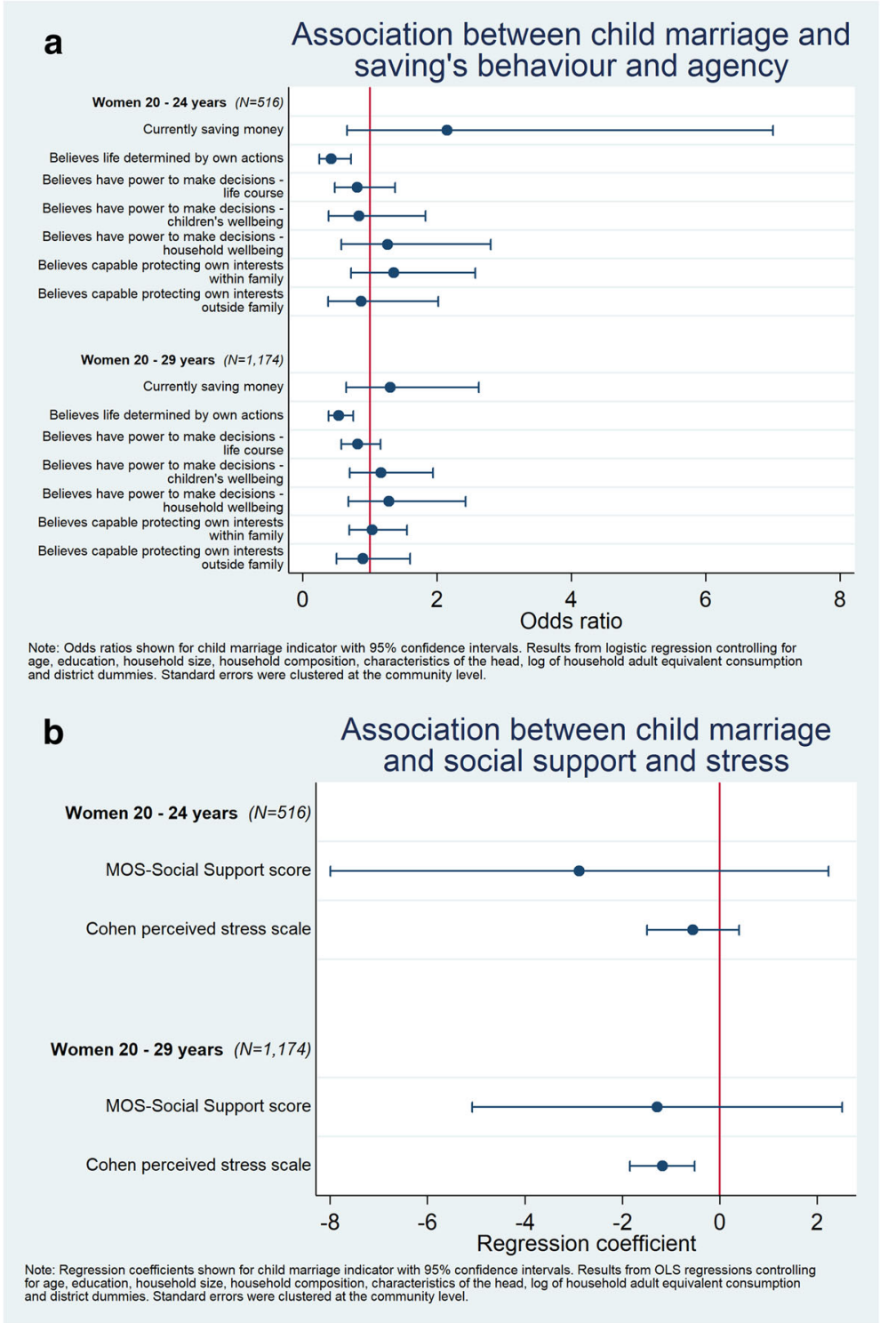

Fig. 3 a Odds ratios (95\% confidence interval) of the association between child marriage and saving's behaviour and agency, Women 2029 years, Ghana LEAP 1000 Baseline. b Regression coefficients (95\% confidence interval) of the association between child marriage and social support and stress, Women 20-29 years, Ghana LEAP 1000 Baseline

there is limited existing evidence on what works best to prevent child marriage. A scan of programmes in 2007 found that there are relatively few programmes operating around the globe given the scope of the problem, and that there are very few that actually attempt to measure the results in terms of reduction of child marriages [6]. Schooling is linked to reductions in child marriage and therefore interventions that address school drop-out among adolescent girls at the secondary level may also reduce early marriage, as evidence has shown in Zimbabwe [39], and Malawi and Uganda [40]. A recent review paper, reviewing 23 programmes addressing child marriage implemented between 1973 and 2009, found that programmes offering incentives (such as cash transfers or school material) and those attempting to empower girls (by providing information and skills and changing attitudes and practices) can be effective at reducing rates of child marriage [41]. However, the limited evidence available examining the ability of government cash transfer programmes in Africa to reduce early marriage is mixed at best and more research is needed $[42,43]$. While the aforementioned research investigates programmes to prevent child marriage, little research is done about what kind of programmes work to help children who are already married. Since this 
study has shown that early childbirth is a major issue among child brides, programmes that increase access to contraception and family planning services should be promising. In addition, livelihood support programmes can help young brides to generate their own income and increase their agency [44].

In Ghana, several efforts are currently underway to combat child marriage. In 2014, the Ministry of Gender, Children and Social Protection set up an Ending Child Marriage Unit, with the mandate to promote and coordinate national efforts to end child marriage in Ghana. More recently, a national campaign was launched to raise awareness about the issue and the government is working on a 10 -year national strategic framework with the primary goal to end child marriages by 2030 [45]. In addition, Ghana is one of the 12 countries participating in the new UNICEF and UNFPA multi-country initiative to accelerate action to end child marriage [46]. While such initiatives and advocacy are an important first step, more research is still needed in Ghana on effective prevention strategies.

\section{Conclusion}

In this study among poor, rural women in Northern Ghana, child marriage was associated with increased difficulty with ADLs, early childbearing, child mortality, lower agency and reduced stress levels. There was no relationship between child marriage and illness, having a valid NHIS card, self-rated health, self-reported improved health compared to 1 year prior, current contraceptive use, unmet need for contraception, saving or social support. These findings support the need for more initiatives aimed at reducing child marriage; however, effective strategies remain elusive. Future research should include studies on the effectiveness of initiatives aimed at mitigating adverse impacts among women and children affected by child marriage as well as efforts around primary prevention.

\section{Endnotes}

${ }^{1}$ Maternal disorders in the Global Burden of Disease report include: maternal haemorrhage; maternal sepsis and other maternal infections; maternal hypertensive disorders; maternal obstructed labour and uterine rupture; maternal abortion, miscarriage and ectopic pregnancy; indirect maternal deaths; late maternal deaths; maternal deaths aggravated by HIV/AIDS; and, other maternal disorders.

${ }^{2}$ All figures in this paragraph are based on authors' calculations from the Ghana Multiple Indicator Cluster Surveys and Ghana Demographic and Health Surveys.
${ }^{3}$ We define adolescents as those between 10 and 19 years of age [47].

${ }^{4}$ The total sample size for the evaluation was established at 2500 households. Hence, the response rate to the survey was nearly universal.

${ }^{5}$ The LEAP programme uses a proxy means test (PMT) with a sharp threshold to determine if households meet the poverty criterion. The PMT takes into account household demographic characteristics, assets and housing conditions. The evaluation is a 'regression discontinuity design'. As such, about $50 \%$ of the sample consists of households just below the threshold with the other $50 \%$ of households scoring above the poverty threshold. For more information about the study design and the sampling, see [27].

${ }^{6} \mathrm{We}$ also considered disability, but the share of women who reported a disability in our sample is very low (1\%) and the estimates are therefore unreliable.

${ }^{7}$ We only consider first-born children here because child brides start bearing children earlier, and hence have more children at the time of the survey and thus higher chance that at least one of their children has died.

${ }^{8}$ Since our sample is not a random sample of the population, this does not necessarily mean that the rate of child marriage has been increasing.

${ }^{9}$ We display our findings graphically, for ease of reading. Full regression output is available from the authors upon request.

${ }^{10}$ The confidence interval for unmet need for contraception is large, due to the low number of women with an unmet need (approximately 3\%). This low value is not uncommon, as the DHS value of a similar indicator is $2.0 \%$ for women 20 to 24 years old and $5.0 \%$ for women 25 to 29 years old [16].

\section{Abbreviations}

ADL: Activities of Daily Living; CRC: Convention on the Rights of the Child; DHS: Demographic and Health Surveys; HIV/AIDS: Human immunodeficiency virus infection and acquired immune deficiency syndrome; ISSER: Institute of Statistical, Social and Economic Research; IUD: Intrauterine Device; LAM: Lactational Amenorrhoea Method; LEAP: Livelihood Empowerment Against Poverty; MICS: Multiple Indicator Cluster Surveys; mMOS-SS: Modified Medical Outcomes Study Social Support Survey; NHIS: National Health Insurance Scheme; OLS: Ordinary Least Squares; OR: Odds Ratio; PSS: Perceived Stress Scale; UNFPA: United Nations Population Fund; UNICEF: United Nations Children's Fund

\section{Acknowledgements}

The authors acknowledge the efforts of the Ghana LEAP 1000 evaluation team: Sudhanshu Handa (UNICEF Office of Research - Innocenti), Isaac Osei-Akoto, Clement Adamba, Joseph K. Darko, Robert Darko Osei, Francis Dompae and Nana Yaw (Institute of Statistical, Social and Economic Research, University of Ghana), Clare Barrington, Sara Abdoulayi, Gustavo Angeles, Averi Chakrabarti and Frank Otchere (Carolina Population Center, University of North Carolina at Chapel Hill), Akalpa J. Akaligaung and Raymond Aborigo (Navrongo Health Research Centre). We are grateful for comments from Rachel Kidman and Annalisa

Caparello on earlier drafts of the manuscript. 


\section{Funding}

This research was funded by CIDA (No. PO7060382 D0000306-001) and USAID (GHA-G-00-07-00007).

\section{Availability of data and materials}

The data that support the findings of this study are property of UNICEF Ghana and the Government of Ghana and restrictions apply to the availability of these data, which were used under license for the current study, and so are not publicly available. However the authors would facilitate data requests by third parties for purposes of replicating the analysis in this article, and Stata do-files are available by the authors upon request.

\section{Authors' contributions}

RG, TP and MYK conceptualized and designed the study. RG analysed the data. $R G, T P$ and MYK interpreted results and drafted the manuscript. All authors read and approved the final manuscript.

\section{Authors' information}

Not applicable.

\section{Ethics approval and consent to participate}

Informed written consent was obtained from all survey respondents. A copy of the signed consent form was left with each respondent including the contact information of the principal investigators. If a respondent was illiterate, the consent form was read out loud, and an additional witness signed the consent form. Ethical approval for the study was granted by the Ethics Committee for the Humanities of the University of Ghana (ECH 093/14-15).

\section{Consent for publication}

Not applicable.

\section{Competing interests}

The authors declare that they have no competing interests.

\section{Publisher's Note}

Springer Nature remains neutral with regard to jurisdictional claims in published maps and institutional affiliations.

\section{Author details}

${ }^{1}$ UNICEF Office of Research-Innocenti, Piazza SS. Annunziata 12, 50122 Florence, Italy. ${ }^{2}$ UNICEF Ghana, 4-8th Rangoon Close, P.O. Box 5051 , Accra-North, Ghana.

Received: 14 February 2017 Accepted: 8 February 2018 Published online: 26 February 2018

\section{References}

1. United Nations. Convention on the rights of the child. New York: United Nations; 1989

2. UNICEF. Ending child marriage: progress and prospects. New York: UNICEF; 2014.

3. Jensen R, Thornton R. Early female marriage in the developing world. Gend Dev. 2003;11(2):9-19.

4. Loaiza E, Wong S. Marrying too young. End child marriage. New York: UNFPA; 2012.

5. Koski A, Clark S, Nandi A. Has child marriage declined in sub-Saharan Africa? An analysis of trends in 31 countries. Popul Dev Rev. 2017;43(1):7-29.

6. Jain S, Kurz K. New insights on preventing child marriage. A global analysis of factors and programs. Washington D.C: International Center for Research on Women; 2007.

7. Nour NM. Child marriage: a silent health and human rights issue. Reviews in. Obstet Gynecol. 2009;2(1):51.

8. Clark S. Early marriage and HIV risks in sub-Saharan Africa. Stud Fam Plan. 2004:35(3):149-60.

9. Kidman R. Child marriage and intimate partner violence: a comparative study of 34 countries. Int J Epidemiol. 2016;46(2):662-75.

10. Santhya K, Ram U, Acharya R, Jejeebhoy SJ, Ram F, Singh A. Associations between early marriage and young women's marital and reproductive health outcomes: evidence from India. Int Perspect Sex Reprod Health. 2010;36(3):132-9.
11. Mokdad AH, Forouzanfar MH, Daoud F, Mokdad AA, El Bcheraoui C, MoradiLakeh M, Kyu HH, Barber RM, Wagner J, Cercy K. Global burden of diseases, injuries, and risk factors for young people's health during 1990-2013: a systematic analysis for the global burden of disease study 2013. Lancet 2016;387(10036):2383-401.

12. Delprato $M$, Akyeampong $K$, Sabates $R$, Hernandez-Fernandez J. On the impact of early marriage on schooling outcomes in sub-Saharan Africa and south West Asia. Int J Educ Dev. 2015;44:42-55.

13. Adhikari RK. Early marriage and childbearing: risks and consequences. In: Bott S, Jejeebhoy S, Shah I, Puri C, editors. Towards adulthood: exploring the sexual and reproductive health of adolescents in South Asia. Geneva: World Health Organization; 2003.

14. Raj A, Saggurti N, Winter M, Labonte A, Decker MR, Balaiah D, Silverman JG. The effect of maternal child marriage on morbidity and mortality of children under 5 in India: cross sectional study of a nationally representative sample. BMJ. 2010;340:b4258.

15. Republic of Ghana. Children's act, 1998 (act 560). Accra: Republic of Ghana; 1998

16. Ghana Statistical Service (GSS), Ghana Health Service (GHS), ICF International. Ghana demographic and health survey 2014 Rockville. Maryland, USA: GSS, GHS, and ICF International; 2015.

17. Peterman A, Schwab B, Roy S, Hidrobo M, Gilligan DO. Measuring Women's Decisionmaking: indicator choice and survey design experiments from cash and food transfer evaluations in Ecuador, Uganda, and Yemen. IFPRI discussion paper 1453. Washington, DC: International Food Policy Research Institute; 2015

18. Alkire S, Meinzen-Dick R, Peterman A, Quisumbing A, Seymour G, Vaz A. The women's empowerment in agriculture index. World Dev. 2013;52:71-91.

19. Parsons J, Edmeades J, Kes A, Petroni S, Sexton M, Wodon Q. Economic impacts of child marriage: a review of the literature. The Review of Faith \& International Affairs. 2015;13(3):12-22.

20. Haushofer J, Shapiro J. The short-term impact of unconditional cash transfers to the poor: experimental evidence from Kenya. Q J Econ. 2016; 131(4):1973-2042.

21. Kling JR. Methodological frontiers of public finance field experiments. Washington D.C: National Bureau of Economic Research; 2007. http://www. nber.org/papers/w12931

22. Hjelm L, Handa S, de Hoop J. Palermo T, on behalf of the Zambia CGP and MCP evaluation teams: poverty and perceived stress: evidence from two unconditional cash transfer programs in Zambia. Soc Sci Med. 2017;177: 110-17.

23. Duflo E. Women empowerment and economic development. J Econ Lit. 2012; 50(4):1051-79.

24. Haushofer J, Fehr E. On the psychology of poverty. Science. 2014;344(6186): $862-7$.

25. Lund C, Breen A, Flisher AJ, Kakuma R, Corrigall J, Joska JA, Swartz L, Patel V. Poverty and common mental disorders in low and middle income countries: a systematic review. Soc Sci Med. 2010;71(3):517-28.

26. Lund C, De Silva M, Plagerson S, Cooper S, Chisholm D, Das J, Knapp M, Patel $\checkmark$. Poverty and mental disorders: breaking the cycle in low-income and middle-income countries. Lancet. 2011:378(9801):1502-14.

27. UNICEF Office of Research - Innocenti, Institute of Statistical Social and Economic Research, University of North Carolina at Chapel Hill, Navrongo Health Research Centre: Ghana LEAP 1000 Programme: Baseline Evaluation Report Florence: UNICEF Office of Research - Innocenti; 2016.

28. UNICEF. Early marriage. A harmful traditional practice: a statistical exploration. New York: UNICEF; 2005.

29. DeSalvo KB, Bloser N, Reynolds K, He J, Muntner P. Mortality prediction with a single general self-rated health question. J Gen Intern Med. 2006;21(3):267-75.

30. Cohen S, Kamarck T, Mermelstein R. A global measure of perceived stress. J Health Soc Behav. 1983;24(4):385-96.

31. Hamad R, Fernald LC, Karlan DS, Zinman J. Social and economic correlates of depressive symptoms and perceived stress in south African adults. J Epidemiol Community Health. 2008;62(6):538-44.

32. Lemma S, Gelaye B, Berhane Y, Worku A, Williams MA. Sleep quality and its psychological correlates among university students in Ethiopia: a crosssectional study. BMC psychiatry. 2012;12(1):1

33. Garcia J, Hromi-Fiedler A, Mazur RE, Marquis G, Sellen D, Lartey A, PérezEscamilla R. Persistent household food insecurity, HIV, and maternal stress in peri-urban Ghana. BMC Public Health. 2013;13(1):1.

34. Moser A, Stuck AE, Silliman RA, Ganz PA, Clough-Gorr KM. The eight-item modified medical outcomes study social support survey: psychometric evaluation showed excellent performance. J Clin Epidemiol. 2012;65(10):1107-16. 
35. Rotter JB. Generalized expectancies for internal versus external control of reinforcement. Psychological monographs: General and applied. 1966;80(1):1.

36. Buller AM, Hidrobo M, Peterman A, Heise L. The way to a man's heart is through his stomach?: a mixed methods study on causal mechanisms through which cash and in-kind food transfers decreased intimate partner violence. BMC Public Health. 2016;16(1):488.

37. Abay K, Berhane G, Woldu Assefa T. Locus of control, hyperbolic preferences, and demand for commitment and saving: evidence from rural farmers in Ethiopia. In: European Association of Environmental and Resource Economists 22nd Annual Conference: 2015. Switzerland: Zurich; 2015.

38. Gage AJ. Association of child marriage with suicidal thoughts and attempts among adolescent girls in Ethiopia. J Adolesc Health. 2013;52(5):654-6.

39. Hallfors D, Cho H, Rusakaniko S, Iritani B, Mapfumo J, Halpern C. Supporting adolescent orphan girls to stay in school as HIV risk prevention: evidence from a randomized controlled trial in Zimbabwe. Am J Public Health. 2011; 101(6):1082-8

40. Behrman JA, Peterman A, Palermo T. Does keeping adolescent girls in school protect against sexual violence? Quasi-experimental evidence from east and southern Africa. J Adolesc Health. 2017;60(2):184-90.

41. Lee-Rife S, Malhotra A, Warner A, Glinski AM. What works to prevent child marriage: a review of the evidence. Stud Fam Plan. 2012;43(4):287-303.

42. Dake F, Natali L, Angeles G, de Hoop J, Handa S, Peterman A. Income transfers, early marriage and fertility in Malawi and Zambia. In: Unpublished manuscript; 2017.

43. Handa S, Peterman A, Huang C, Halpern C, Pettifor A, Thirumurthy H. Impact of the Kenya cash transfer for orphans and vulnerable children on early pregnancy and marriage of adolescent girls. Soc Sci Med. 2015;141:36-45.

44. Santhya K, Erulkar A. Supporting married girls: calling attention to a neglected group. Transitions to adulthood brief no 3. New York: Population Council; 2011.

45. Ghana Launches African Union Campaign to End Child Marriage [http:// www.girlsnotbrides.org/ghana-launches-national-campaign-to-end-childmarriage/]. Accessed 20 Oct 2016

46. New multi-country initiative will protect millions of girls from child marriage - UNICEF/UNFPA [http://www.unicef.org/media/media_90394. html]. Accessed 20 Oct 2016.

47. UNICEF. State of the World's children 2011. Adolescence: an age of opportunity. In. New York: United Nations Children's Fund; 2011.

\section{Submit your next manuscript to BioMed Central and we will help you at every step:}

- We accept pre-submission inquiries

- Our selector tool helps you to find the most relevant journal

- We provide round the clock customer support

- Convenient online submission

- Thorough peer review

- Inclusion in PubMed and all major indexing services

- Maximum visibility for your research

Submit your manuscript at www.biomedcentral.com/submit 